\title{
Second cancer case halts gene-therapy trials
}

\section{Erika Check, Washington}

The world of gene therapy was shaken last year when a child treated in a French trial developed leukaemia. Researchers had pinned their hopes on this being an unfortunate one-off. Now those hopes have been dashed with the emergence of a second, almost identical case that could jeopardize the future of gene therapy.

The latest case centres on a three-year-old boy treated in a gene-therapy trial led by Alain Fischer at the Necker Hospital for Sick Children in Paris. Just under three years ago, the child was cured of severe combined immunodeficiency disease (SCID), a condition that disrupts the development of the immune system. But researchers revealed last week that the boy was diagnosed with leukaemia just days before Christmas.

The news last August that a child in Fischer's trial had developed cancer left nations divided over their regulatory response (see Nature 419, 545-546; 2002). This time there was greater accord. Britain has stopped the world's only active SCID trial, and the US Food and Drug Administration (FDA) has suspended more than two dozen similar gene-therapy trials in a variety of diseases - trials it had allowed to continue after August's incident.

The setback is all the more serious because it arises in a trial that was widely viewed as gene therapy's only true success. Fisher has so far cured nine boys - including the two who now have leukaemia - out of 11 patients. And when the first child was diagnosed with cancer, some argued that it was an isolated event (see Nature 420, 595; 2002).

But Christof von Kalle of the Cincinnati Children's Hospital says analysis of the two boys' cells shows that the same molecular events probably caused the cancers. In both boys, the retroviral vector used to deliver the corrective gene has integrated itself into a stretch of DNA in or near a gene called LMO2, which can cause childhood leukaemias. Scientists are now satisfied that the disease behaves enough like leukaemia to describe it as such.

Kalle estimates that the vector is likely to insert itself near to $\mathrm{LMO} 2$ in between 1 -in50,000 and 1-in-100,000 cells. And because each child in the trial receives a dose of about a million corrected cells, each patient could carry at least one cell with the vector near LMO2. Kalle is analysing samples from all of the children - about 15 in all - who have been treated in SCID gene-therapy trials to find out whether they are carrying such cells.

In the meantime, an FDA advisory committee on gene therapy will meet on $28 \mathrm{Feb}$ ruary to decide what the adverse event means for other studies. The American Society of Gene Therapy will also convene a committee

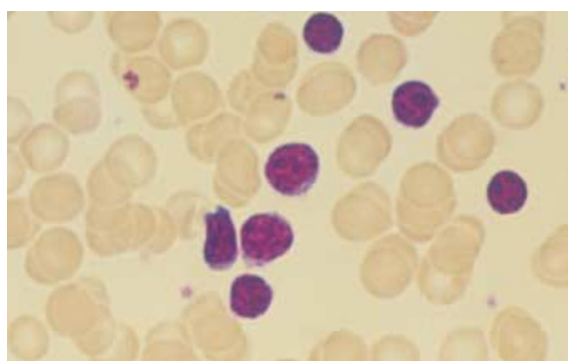

Blood cancer: leukaemia has been detected in two patients who have received gene therapy.

to examine data from human and animal trials of retroviral vectors. And the National Institutes of Health's Recombinant DNA Advisory Committee (RAC) postponed its planned meeting on 17 January, but will convene shortly to discuss these issues.

At their last meetings, both the FDA committee and the $\mathrm{RAC}$ recommended that gene therapy in SCID could proceed with appropriate monitoring and informed-consent programmes. RAC chair Ted Friedmann of the University of California, San Diego, says that this approach is "still valid", although it could be revised in light of the new case.

The case is an enormous setback for the field - and for patients with SCID. "The treatment works very well," Fischer says, "but the risk is not acceptable."

\section{Meeting aims to find brain's benchmarks for beauty}

\section{Jonathan Knight, San Francisco}

Are our preferences in music and art learned or innate? Neuroscientists met with artists, musicians and architects at the University of California, Berkeley, on 11 January in an effort to discover some clues to the neurological basis of taste.

Many experts believe that our artistic

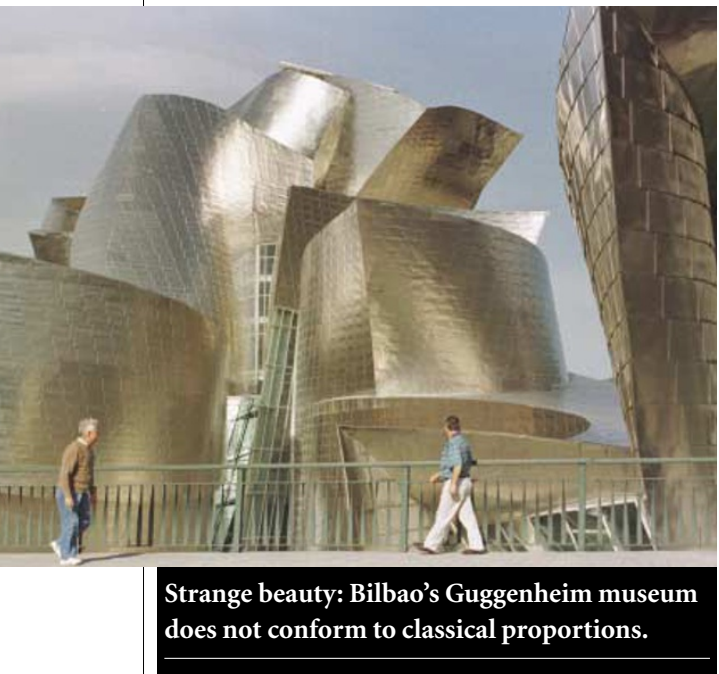

choices are entirely dependent on cultural influences. But proponents of neuroaesthetics think that there are pointers to taste, and that studying the brain will help to find them.

The most noted results in this new field have been in music, although even these are inconclusive. Mark Tramo, director of Harvard's Institute for Music and Brain Science, pointed to studies by Marcel Zentner and Jerome Kagan of Harvard University suggesting that infants find more dissonant musical intervals, such as those known as tritones, less pleasing than consonant ones such as perfect fifths (Nature 383, 29; 1996).

Tramo said he has shown that perfect fifths produce smoother firing patterns in auditory nerves than tritones do (M. J. Tramo et al. Ann. NY Acad. Sci. 930, 92-116; 2001). Although this does not explain why one interval is more pleasing than another, Tramo said, it sheds light on how the auditory system responds to different aspects of music.

Progress is sketchier in the visual arts. John Eberhard, who directs research planning at the American Institute of Architects (AIA), suggested that a set of proportions known as the 'golden section', which is commonly incorporated in classical architecture, might be universally pleasing to the mind.

But AIA president Gordon Chong pointed out at the meeting that these proportions are completely absent from successful modern buildings such as Frank Gehry's Guggenheim museum in Bilbao, Spain.

Chong remains optimistic that neurobiologists may one day help architects to design soothing hospitals, for example, or stimulating schools. "Many of us look forward to a time when we design spaces more scientifically," he says.

According to Harrison Fraker, dean of Berkeley's College of Environmental Design, current architectural theory holds that taste is learned and relative, not innate. But neuroaesthetes counter that even learned taste must have a neurological basis.

Semir Zeki of University College London, who helped to organize the meeting, says that neuroaesthetics is "taking off in a big way". But for now, he says, "we have much more to learn from artists than they have to learn from us".

http://brain.berkeley.edu/ plaisir/conf.htm 